\title{
Effect of Substrate on CuS/PVA Nanocomposite Thin Films Deposited on Glass and Silicon Substrate
}

\author{
Sandhya Yadav, Parmendra Kumar Bajpai* \\ Advance Materials Research Laboratory, Department of Pure \& Applied Physics, Guru Ghasidas \\ Vishwavidyalaya, Bilaspur, India \\ Email: ^bajpai.pk1@gmail.com
}

How to cite this paper: Yadav, S. and Bajpai, P.K. (2018) Effect of Substrate on CuS/PVA Nanocomposite Thin Films Deposited on Glass and Silicon Substrate. Soft Nanoscience Letters, 8, 9-19. https://doi.org/10.4236/snl.2018.82002

Received: February 15, 2018

Accepted: April 27, 2018

Published: April 30, 2018

Copyright (c) 2018 by authors and Scientific Research Publishing Inc. This work is licensed under the Creative Commons Attribution International License (CC BY 4.0).

http://creativecommons.org/licenses/by/4.0/

\section{c) (i) Open Access}

\begin{abstract}
Transition metal chalcogenide nanocomposite thin films deposited by chemical routes are currently attracting wide attention being inexpensive, simple and have utility for large area applications. The role of substrate becomes very important in film deposition as well as in controlling their properties due to strain induced properties modification and lattice mismatch. $\mathrm{CuS/PVA}$ nanocomposite thin films were successfully deposited on glass and silicon substrates using sol-gel technique. Thin films were characterized by $\mathrm{X}$-ray diffraction (XRD), atomic force microscopy (AFM), UV-visible (UV-VIS) and Raman spectroscopy. Structural data confirm the amorphous nature of as grown films which transform into crystalline films after annealing at $200^{\circ} \mathrm{C}$. The degree of crystallinity seems to be better in film deposited on silicon substrate in comparison to those grown over glass substrate with average crystallite sizes $\simeq 4.00 \mathrm{~nm}$ and $7.00 \mathrm{~nm}$ for films deposited on glass and silicon substrate respectively. Atomic force microscopy (AFM) images in dynamic as well as contact modes display nanoparticles embedded in polymer network. The films surface roughness parameters quantitatively estimated from AFM micrographs are compared. Raman spectra show a sharp peak at $\simeq 474 \mathrm{~cm}^{-1}$ assigned to $\mathrm{S}$-S stretching mode of $\mathrm{S}_{2}$ ions in films grown on both substrates and associated as due to presence of hexagonal (covellite) crystal structure. Optical band gaps of thin film on glass and silicon substrate are $2.10 \mathrm{eV}$ and $2.02 \mathrm{eV}$ respectively. The effect of substrate on the measured properties is discussed.
\end{abstract}

\section{Keywords}

Copper Sulfide, Nanocomposite Thin Films, Surface Morphology, Optical Band Gap, Atomic Force Microscopy, Raman Spectra 


\section{Introduction}

Copper sulfide belonging to IB-VIA group is an important and attractive material due to the wide range of applications in optical and electrical devices, and due to relatively non-toxic nature [1] [2] [3]. However, due to the presence of 3d electrons, copper has complex chemical nature and forms non-stoichiometric chalcogenide phases [4]. At room temperature, at least five stable phases viz. $\mathrm{CuS}$ (covellite), $\mathrm{Cu}_{1.75} \mathrm{~S}$ (anilite), $\mathrm{Cu}_{1.8} \mathrm{~S}$ (digenite), $\mathrm{Cu}_{1.96} \mathrm{~S}$ (djurleite), $\mathrm{Cu}_{2} \mathrm{~S}$ (chalcocite) with crystal structure vary from hexagonal to orthogonal. Therefore, growing nanoparticles with pure covellite phase becomes albeit tedious [5] [6] [7] [8]. CuS is a p-type semiconductor with the reported band gap ranging from $1.2 \mathrm{eV}$ to $2.5 \mathrm{eV}$ due to non-stoichiometric composition of $\mathrm{Cu}_{x} \mathrm{~S}(1 \leq x \leq 2)$ [9]. Proper stoichiometric compositions of nanoparticles/nano thin films are important in order to understand the effect of nano size on the electronic optical properties. Currently, nanocomposites of polymers and semiconductors have been an object of extensive research due to the possibility to change the physico-chemical properties of the materials. Various factors influence the physico-chemical properties of nanocomposite including the particle separation, the inter-phase interaction, the nature of polymer matrix and the substrate used for growing the nanocomposite thin film, etc. [10]. Polymer matrix provides stability, long shelf life and good control over the growth of nanoparticles. In addition, nanosized particles enhance their optoelectronic properties, allowing coupling between mechanical and optoelectronic properties. The polymer host matrix confines the growth of nanoparticles and prevents aggregation [11]. The properties of particulate polymer nanocomposite mainly depend on the particle shape, size, concentration and the way in which the particles are dispersed and interact with the polymer matrix.

It has been shown that the electrical, optical and structural properties of chalcogenide nanoparticles get affected when embedded in polymeric matrix; however, the nanocomposite based on pure phase $\mathrm{CuS}$ with polymers are sporadic only. Poly (vinyl alcohol) (PVA) is a hydrophilic polymer. PVA hydrogel is most promising polymers due to its unique properties such as high transmittance, easy processability, noncorrosive nature and good thermal stability over a wide range of temperature, making it an ideal matrix for optoelectronic applications [12] [13].

Previously, CdS/PVA nanocomposite thin films were synthesized [14] on glass substrate without using any complexing agent. A comparative study of $\mathrm{CuS}$ thin film without any composites has been reported [15] using glass and FTO coated glass as substrates. CuS nanoparticles embedded in poly (vinyl alcohol) nanofibers were also reported [16] using electrospinning method. Spherical copper sulfide nanoparticle was dispersed in PVA fibres with average diameter about 15 $25 \mathrm{~nm}$. However, CuS/PVA nanocomposite thin films deposition on glass and silicon substrate has not been reported to the best of our knowledge. In this paper we report synthesis of copper sulfide nanocomposite thin film on glass and 
silicon substrate using spin coating via sol-gel technique. As deposited and annealed CuS/PVA nanocomposite thin films were characterized by XRD, AFM, UV-visible and micro Raman spectroscopy. The effect of substrate on structural, micro-structural, surface roughness and optical band gap are investigated and discussed.

\section{Experimental Details}

\subsection{Material}

Copper sulphate pentahydrate $\left(\mathrm{CuSO}_{4} \cdot 5 \mathrm{H}_{2} \mathrm{O}, 99 \%\right)$, lauryl sulphate (SDS), poly (vinyl alcohol) (PVA), sodium sulfide $\mathrm{Na}_{2} \mathrm{~S}$ (Merck 98\%), diluted $\mathrm{H}_{2} \mathrm{SO}_{4}$ are taken as precursors. All the used chemical were analytical grade reagents and used as received.

\subsection{Preparation of CuS/PVA Nanocomposite Thin Films}

The substrate was cut in slides of square shape, cleaned ultrasonically for 10 minute first in acetone and subsequently in deionized water. Finally substrates were dried using hot plate. For the synthesis of CuS/PVA nanocomposite thin film, 0.261-gram copper sulphate pentahydrate $\left(\mathrm{CuSO}_{4} \cdot 5 \mathrm{H}_{2} \mathrm{O}\right)$ as cationic precursor and 0.0159 gram of lauryl sulphate (SDS) were dissolved in $30 \mathrm{~mL}$ distilled water and kept under continuous magnetic stirring for 1 hour. 1.500 gram of PVA (5 weight\%) was dissolved in the above prepared solution. The solution was heated for $6 \mathrm{~h}$ under continuous magnetic stirring at $90^{\circ} \mathrm{C}$. The prepared solution was cooled down to room temperature under stirring for $24 \mathrm{~h}$. After 24 $\mathrm{h}$ we get the solution of $\mathrm{CuSO}_{4} / \mathrm{PVA}$. After that the solution of $\mathrm{CuSO}_{4} / \mathrm{PVA}$ was exposed by $\mathrm{H}_{2} \mathrm{~S}$ to make the solution of CuS/PVA. Prepared solution was used for the synthesis of thin films. Glass and silicon was used as substrate for the deposition of $\mathrm{Cu}_{x} \mathrm{~S}$ thin film. Deposited CuS/PVA nanocomposite thin films were annealed at $100^{\circ} \mathrm{C}, 150^{\circ} \mathrm{C}$ and $200^{\circ} \mathrm{C}$ for 2 hour. This range of annealing temperature was chosen because $\mathrm{CuS}$ got decompose at $\sim 220^{\circ} \mathrm{C}$. Thin film deposited at $200^{\circ} \mathrm{C}$ was used for the further characterization. $\mathrm{H}_{2} \mathrm{SO}_{4}$ and $\mathrm{Na}_{2} \mathrm{~S}$ were used for synthesis of $\mathrm{H}_{2} \mathrm{~S}$ gas using keeps apparatus.

\subsection{Characterization of CuS/PVA Nanocomposite Thin Films}

Deposited nanocomposite thin films were characterized by X-ray diffraction (XRD) using Rigaku smart lab X-ray diffractometer with a $\mathrm{CuK}_{\alpha}$ monochromatic radiation source $(\lambda=1.54059 \AA)$ in the $2 \theta$ range $20^{\circ}-80^{\circ}$; the tube voltage was $40 \mathrm{kV}$ and current $200 \mathrm{~mA}$ employing a scanning speed of 2 degree/min. Analysis of surface morphology were carried out usingatomic force microscopy (AFM) using SPM 9600 Shimadzu contact mode as well as dynamic mode. The UV-Vis absorption spectra in the range $200-800 \mathrm{~nm}$ was taken by UV-visible spectrophotometer Shimadzu, UV1700 Pharma spec. Room temperature unpolarized Raman spectra were measured using Technos STR-500 micro Raman spectrometer. 


\section{Result and Discussion}

\subsection{Structural Studies}

The degree of crystallinity and phase of nanocomposite thin films were deposited on glass and silicon substrate characterized by X-ray diffraction as shown in Figure 1. XRD patterns of as deposited thin films of CuS/PVA nanocomposite on both glass and silicon substrates do not show any XRD peak corresponding to $\mathrm{CuS}$ indicating that as grown films are amorphous in nature. XRD patterns for thermally annealed nanocomposite thin films (annealed at $200^{\circ} \mathrm{C}$ ) deposited on both glass and Si-substrates substrates show sharp diffraction peaks. Thus, thermal annealing transforms the amorphous films into crystalline. XRD peaks

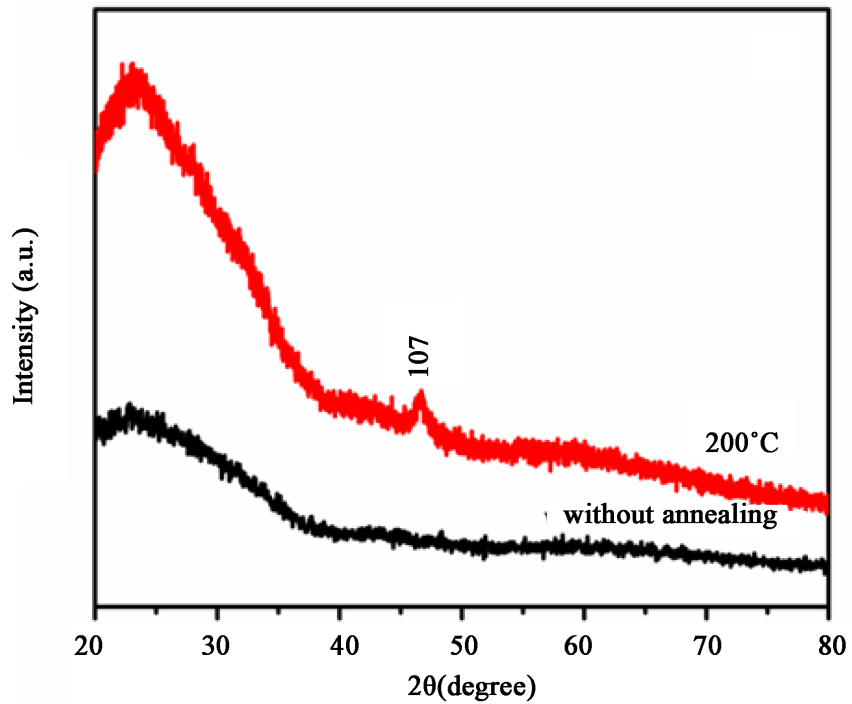

(a)

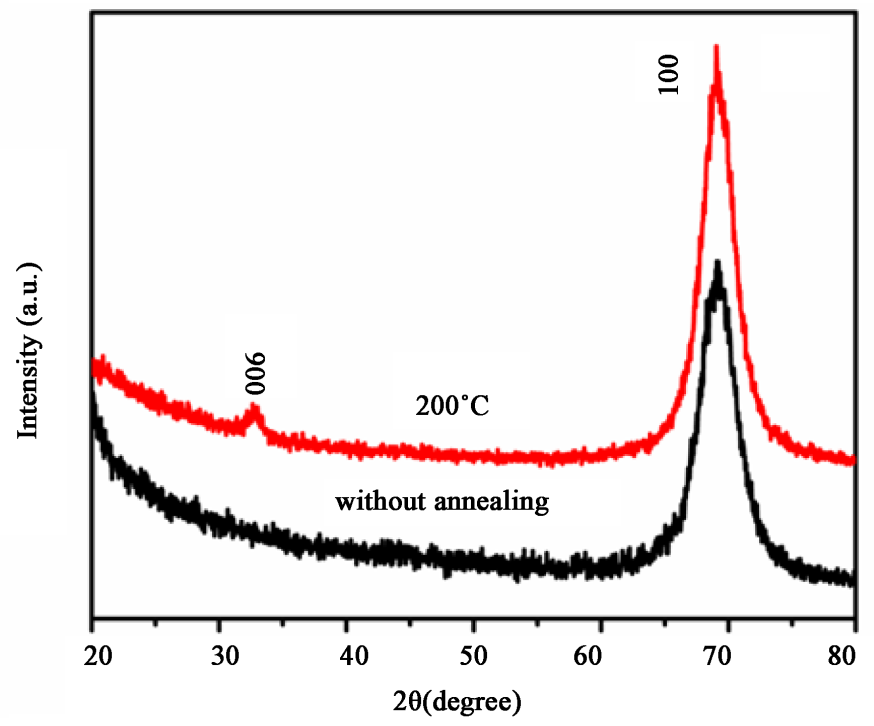

(b)

Figure 1. XRD pattern of CuS/PVA nanocomposite thin film on (a) glass substrate, (b) silicon substrate. 
in annealed films could be assigned to hexagonal crystal structure covellite phase with space group 194:P63/mmc.

In Figure 1(a), the amorphous background also increases in annealed film grown on glass substrate. A broad hump in the range $2 \theta$ from $20^{\circ}-35^{\circ}$ is due to the amorphous glass substrate [17]. It can be inferred that film deposited on glass substrate have more disorder in comparison to the one deposited on silicon substrate. In Figure 1(b) film grown on silicon substrate shows hexagonal crystal structure with covellite phase with plane (006). Another peak (100) is due to the silicon substrate [18] [19]. No diffraction peaks detected corresponding to the $\mathrm{CuO}$, impurities or other phases.

The average crystallite size of nanocomposite thin films were calculated by Scherrer equation

$$
D=0.9 \lambda / \beta \cos \theta
$$

Here, $D$ is crystallite size, $\lambda$ is wavelength of X-ray (1.5409 $\AA$ ), $\beta$ is full width at half maximum of the intense peak and $\theta$ the Bragg's angle. Using Equation (1), average crystallite size of CuS/PVA nanocomposite thin film deposited on glass and silicon substrate is $4.00 \mathrm{~nm}$ and $7.00 \mathrm{~nm}$ respectively.

\subsection{Atomic Force Microscopy}

Surface roughness and morphology become very important for device applications in thin films. AFM measurements were carried out to find the surface morphological features of nanocomposite thin films. AFM micrographs measured in contact mode in two and three dimensions with $(2.5 \mu \mathrm{m} \times 2.5 \mu \mathrm{m})$ resolution for annealed film deposited on glass substrate are shown in Figure 2(a), where as the same for films deposited on silicon substrate are depicted in Figure 2(b). The micrographs in contact modes show polymer network with embedded nanoparticles. The nanocomposite thin film grown on glass substrate has more porous area than those grown over silicon substrate. Further, the embedded nanoparticles of almost homogeneous size are also visible in both images. The micrograph measured in dynamic mode $(1.87 \mu \mathrm{m} \times 1.87 \mu \mathrm{m})$ are shown in Figure 2 (c) for film deposited on glass substrate, whereas the same for films deposited on silicon substrate $(3.75 \mu \mathrm{m} \times 3.75 \mu \mathrm{m})$ are depicted in Figure $2(\mathrm{~d})$. The surface morphology observed in dynamic mode is densely packed particles without any apparent porosity. There exist significant different in surface morphology of the films grown on two substrates. Whereas, the particles are of uniform size grown on glass substrate, those grown on silicon substrate have large particles embedded in small particles matrix. As is well known, the surface morphology in contact mode is influenced by jump to contact phenomenon giving rise to artefacts and dynamic mode is preferred to avoid this phenomenon. The surface roughness $\left(R_{a}\right)$, surface height $\left(R_{z}\right)$, and root mean square roughness $\left(\mathrm{R}_{\mathrm{q}}\right)$ are quantitatively estimated from these AFM micrographs and compared in Table 1. 


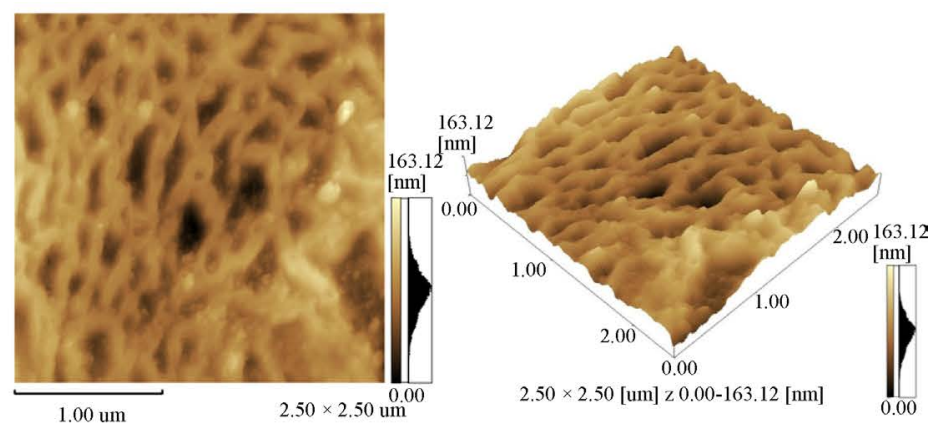

(a)

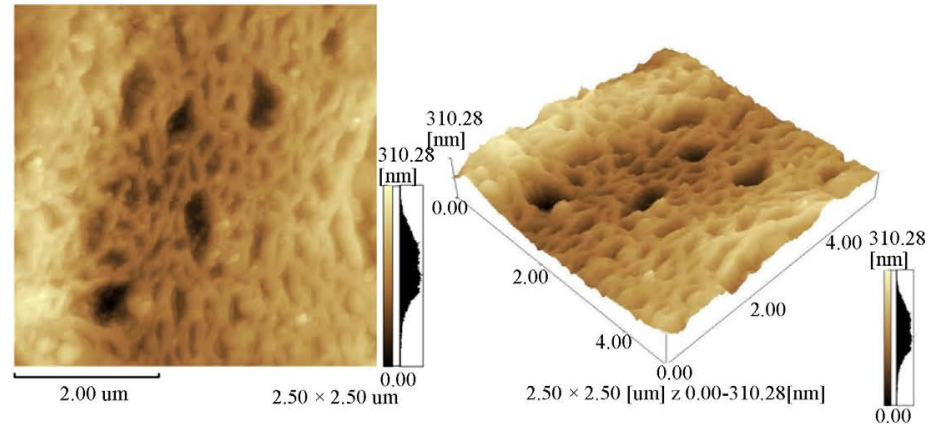

(b)

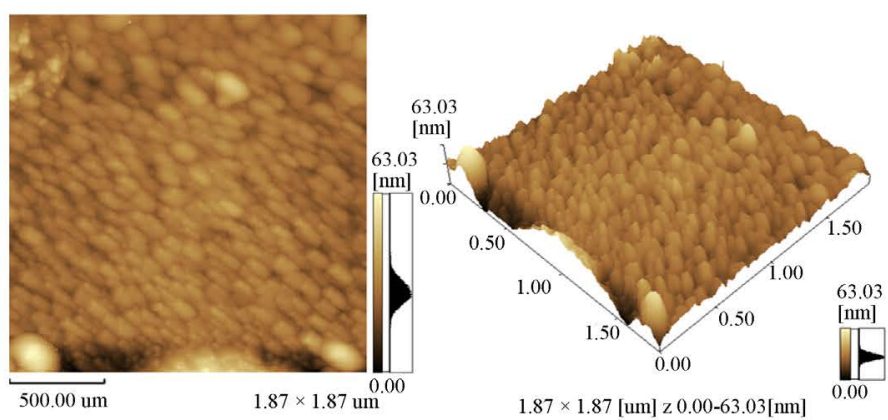

(c)

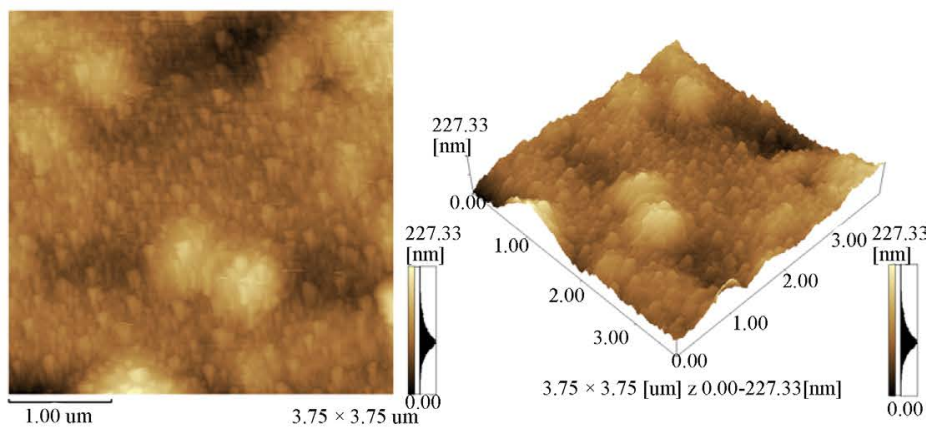

(d)

Figure 2. (a) AFM micrograph of CuS/PVA nanocomposite thin film deposited on glass substrate in two and three dimensional using contact model; (b) AFM micrograph of CuS/PVA nanocomposite thin film deposited on silicon substrate in two and three dimensional using contact mode; (c) AFM micrograph of CuS/PVA nanocomposite thin film deposited on glass substrate in two and three dimensional using dynamic mode; (d) AFM micrograph of CuS/PVA nanocomposite thin film deposited on silicon substrate in two and three dimensional using dynamic mode. 
Table 1. The surface roughness $(\mathrm{Ra})$, surface height $(\mathrm{Rz})$, and root mean square roughness $(\mathrm{Rq})$ analysis of CuS/PVA nanocomposite thin films.

\begin{tabular}{cccccc}
\hline S.N. & \multirow{2}{*}{ Mode } & Substrate & \multicolumn{2}{c}{ Surface height } \\
$(\mathrm{Rz}) \mathrm{nm}$ & $\begin{array}{c}\text { Surface roughness } \\
(\mathrm{Ra}) \mathrm{nm}\end{array}$ & $\begin{array}{c}\text { Route mean square } \\
\text { roughness (Rq) nm }\end{array}$ \\
\hline 1. & Contact mode & glass & 98.91 & 20.54 & 22.17 \\
2. & & silicon & 115.56 & 23.78 & 29.27 \\
3. & \multirow{2}{*}{ Dynamic mode } & glass & 76.67 & 14.98 & 18.62 \\
4. & & silicon & 105.22 & 21.16 & 28.13 \\
\hline
\end{tabular}

\subsection{Optical Properties}

UV-visible absorption technique is most important methods for the determination of optical properties of semiconductor materials. UV-visible absorption spectra of nanocomposite thin films were recorded in the range of $200-800 \mathrm{~nm}$ (figure not shown for the sake of brevity). The energy band gaps of semiconductor thin films were calculated by absorption spectra fitting (ASF). In ASF procedure optical band gap can be calculated directly from absorbance data without measuring the thickness of the sample. The value of parameter $\lambda_{g}$ can be obtained by extrapolating the $\left(\frac{A b s(\lambda)}{\lambda}\right)^{\frac{1}{m}} v s \cdot \frac{1}{\lambda}$ plot linearly at $\left(\frac{A b s(\lambda)}{\lambda}\right)^{\frac{1}{m}}=0$. The optical band gap energy (e.g., in electron volt), can be calculated as $E_{g}=\frac{1239.83}{\lambda_{g}}$. The least square fitting of the absorption data for nanocomposite thin films have best fitting for $m=1 / 2[20]$. The $\left(\frac{A b s(\lambda)}{\lambda}\right)^{2} v s \cdot \frac{1}{\lambda}$ curves for copper sulfide thin film are shown in Figures 3(a)-(b). The energy band gap for the nanocomposite thin film deposited on glass and silicon substrate is $2.10 \mathrm{eV}$ and $2.02 \mathrm{eV}$ respectively. The observed band gap is in close conformity with those reported earlier for CuS nano-particles. The slightly higher values of estimated band gap in films deposited on glass substrate is in tune with the smaller crystallite size of these films in comparison to those grown on Si-substrate as estimated from XRD data.

\subsection{Raman Spectroscopy}

Laser Raman spectroscopy is a suitable and effective tool to characterize the local disorder, crystalline symmetry and strain in the thin films. Room temperature Raman spectra of copper sulfide nanocomposite thin film deposited on glass and silicon substrate were show in Figure 4.

Figure 4(a) shows Raman spectra of CuS/PVA nanocomposite thin film grown on glass substrate. It shows Raman band at $474 \mathrm{~cm}^{-1}$ which is assigned to the S-S stretching mode indicating the covellite CuS phase. In Figure 4(b) Raman spectrum of nanocomposite thin film deposited in silicon substrate, also 


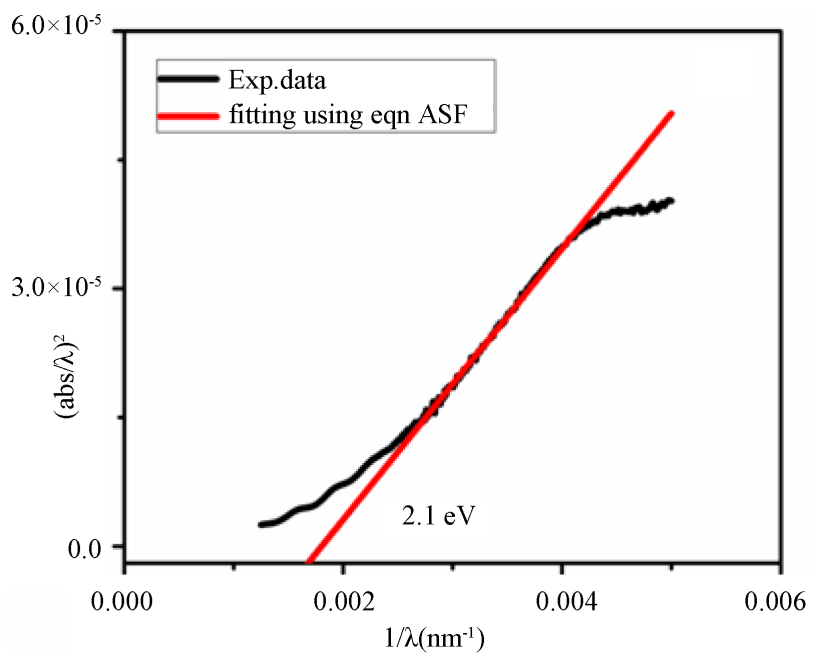

(a)

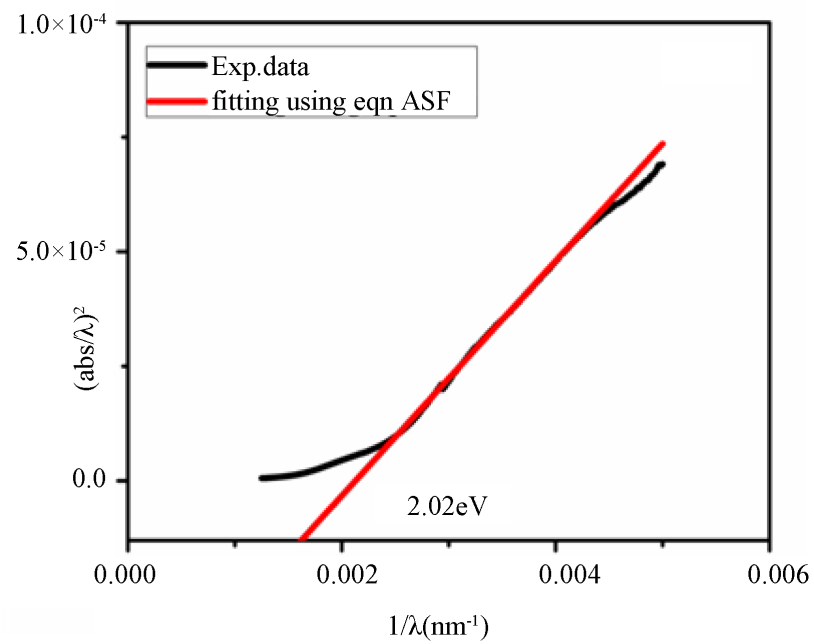

(b)

Figure 3. Absorption spectra fitting (ASF) for CuS/PVA nanocomposite thin film on (a) glass; (b) silicon substrate.

shows a sharp band at $474 \mathrm{~cm}^{-1}$ along with a high intensity band at $522 \mathrm{~cm}^{-1}$ due to the silicon substrate. Raman bands in both films show bands at the same wavenumber $\simeq 474 \mathrm{~cm}^{-1}$, corresponding to the covellite phase as earlier reported [21]. However, the asymmetric nature of band along with increase in back ground noise with increasing wave number is marked in film grown on glass substrate in comparison to the one grown on Si-substrate. This further corroborates the structural evidence of disordered nature of thin film deposited on glass substrate.

Summarily, the structural, morphological and optical characterization of deposited nano-composite thin films on two substrates reveals the role of substrate in film deposition. The films grown on amorphous glass substrate are relatively disordered, have smaller crystallite size and surface roughness in comparison to the one deposited on crystalline Si-substrate. 


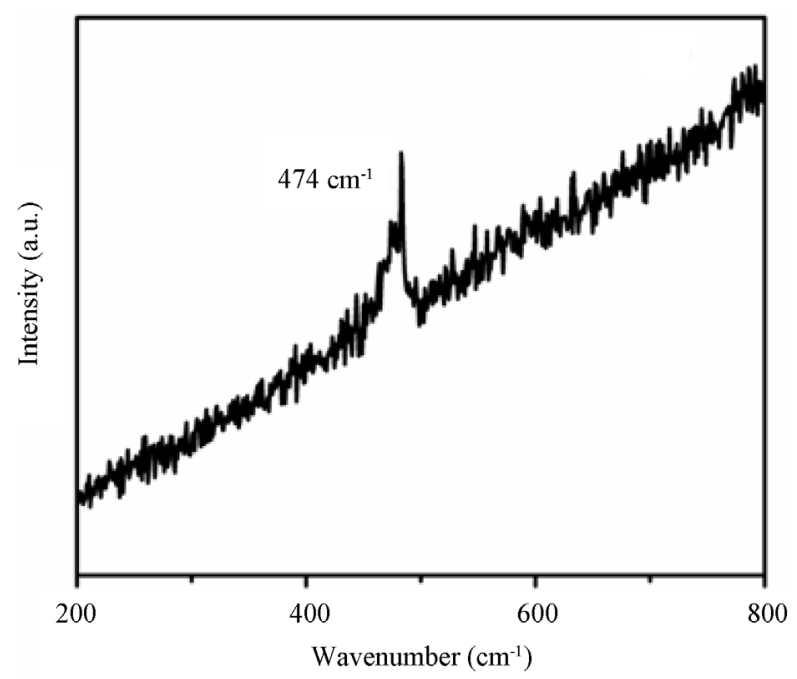

(a)

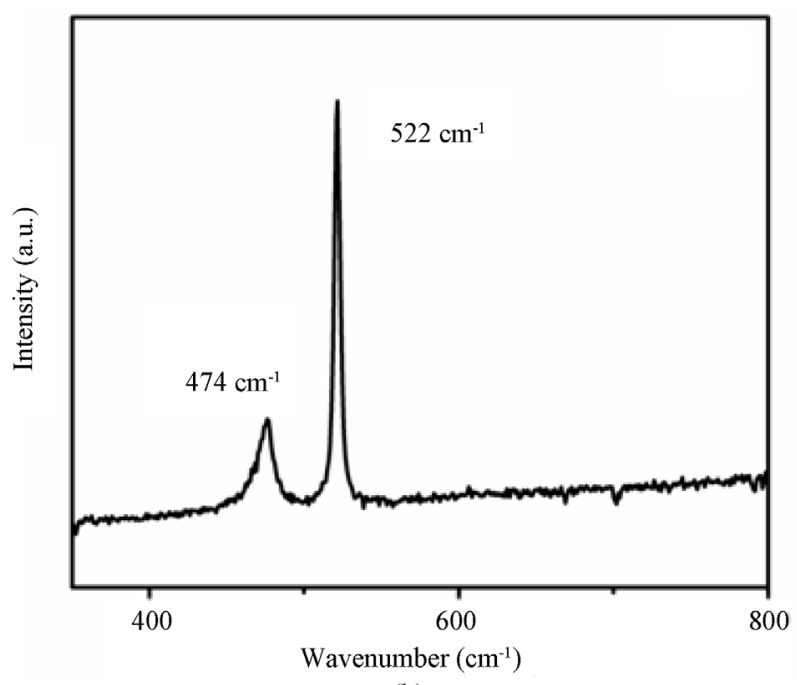

(b)

Figure 4. Raman spectra of CuS/PVA nanocomposite thin film on (a) glass; (b) silicon substrate.

\section{Conclusion}

Copper sulfide nanocomposite thin films on glass and silicon substrate were successfully deposited using sol-gel technique. Structural, morphological and optical properties study has been probed using X-ray diffraction, atomic force microscopy, UV-visible spectroscopy and Raman spectroscopy. Annealed nanocomposite thin films show covellite phase without presence of any impurities or other phases. AFM reveals that particles are equally distributed all over the surface of film in glass and silicon substrate. Surface is relatively uniform and particles agglomeration is avoided. Surface roughness and RMS values are less for the nanocomposite thin film grown on the glass substrate as compare to the silicon substrate. Optical spectra revealed that direct energy band gap found $2.10 \mathrm{eV}$ and $2.02 \mathrm{eV}$ for glass and silicon substrate. Raman spectral features support the 
covellite phase of nanocomposite thin films and the presence of disorder in the film deposited on glass substrate.

\section{Acknowledgements}

P. K. Bajpai is thankful to Department of Science \& Technology, Govt. of India for providing FIST support and University Grant Commission (UGC) No. 530/2/DRS/2012(SAP-I) dated 8.5.2012, New Delhi, India for SAP program to the Department of Pure \& Applied Physics, Guru Ghasidas Vishwavidyalaya, Bilaspur, India. Sandhya Yadav is thankful to UGC for providing non-NET fellowship for this work.

\section{Conflicts of Interest}

The authors declare no conflicts of interest regarding the publication of this paper.

\section{References}

[1] Chaki, S.H., Deshpande, M.P. and Tailor, J.P. (2014) Characterization of CuS Nanocrystalline Thin Films Synthesized by Chemical Bath Deposition and Dip Coating Technique. Thin Solid Films, 550, 291-297. https://doi.org/10.1016/j.tsf.2013.11.037

[2] Dhondge, A.D., Gosavi, S.R., Gosavi, N.M., Sawant, C.P., Patil, A.M., Shelke, A.R. and Deshpande, N.G. (2015) Influence of Thickness on the Photosensing Properties of Chemically Synthesized Copper Sulfide Thin Films. World Journal of Condensed Matter Physics, 5, 1-9. https://doi.org/10.4236/wjcmp.2015.51001

[3] Bajpai, P.K., Yadav, S., Tiwari A. and Virk H.S. (2015) Recent Advances in the Synthesis and Characterization of Chalcogenide Nanoparticles. Solid State Phenomena, 222, 187-233. https://doi.org/10.4028/www.scientific.net/SSP.222.187

[4] Kundu, M., Hasegawa, T., Terabe K., Yamamoto K. and Aono, M. (2008) Structural Studies of Copper Sulfide Films: Effect of Ambient Atmosphere. Science and Technology of Advanced Materials, 9, 1-6. https://doi.org/10.1088/1468-6996/9/3/035011

[5] Maji, S.K., Mukherjee, N., Dutta, A.K., Srivastava, D.N., Paul, P., Karmakar, B., Mondal, A. and Adhikary, B. (2011) Deposition of Nanocrystaline CuS Thin Film From a Single Precursor: Structural, Optical and Electrical Properties. Materials Chemistry and Physics, 130, 392-397.

https://doi.org/10.1016/j.matchemphys.2011.06.057

[6] Lindroos, S., Arnold A. and Leskel M. (2000) Growth of CuS Thin Films by the Successive Ionic Layer Adsorption and Reaction Method. Applied Surface Science, 158, 75-80. https://doi.org/10.1016/S0169-4332(99)00582-6

[7] Yadav, S. and Bajpai, P.K. (2017) Synthesis of Copper Sulfide Nanoparticles: pH Dependent Phase Stailization. Nano-Structures \& Nano-Objects, 10, 151-158. https://doi.org/10.1016/j.nanoso.2017.03.009

[8] Offiah, S.U., Ugwoke, P.E., Ekwealor, A.B.C., Ezugwu, S.C. and Osuji, R.U. (2012) Structural and Spectral Analysis of Chemical Bath Deposited Copper Sulfide Thin Films for Solar Energy Conversions. Digest Journal of Nanomaterials and Biostructures, 7, 165-173.

[9] Huse, N.P., Dive, A.S., Gattu, K.P. and Sharma, R. (2011) An Experimental and 
Theoretical Study on Soft Chemically Grown CuS Thin Film for Photosensor Application. Mareials Science in Semiconductor Processing, 67, 62-68. https://doi.org/10.1016/j.mssp.2017.05.010

[10] Muradov, M.B., Abdinov, A.S., Hajimamedov, R.H. and Eyivazova, G.M. (2009) Dielectric Properties of Nanocomposites on the Basis of Copper Sulfide Nanoparticles and a Polymer Matrix. Surface Engineering and Applied Electrochemistry, 45, 167-170. https://doi.org/10.3103/S1068375509020161

[11] Al-Taay, H.F., Shanan, Z.J., Khaddum, E., Abdalameer, N.K., Talal, S. and Nader, R. (2016) Optical and Sructural Properties of CdS/PVA Nanocomposites. IOSR Journal of Applied Physics, 8, 73-79. https://doi.org/10.9790/4861-0805027379

[12] Abdullah, O.G. and Saleem, S.A. (2016) Effect of Copper Sulfide Nanoparticles on the Optical and Electrical Behavior of Poly(Vinyl Alcohol) Films. Journal of Electronic Materials, 45, 5910-5920. https://doi.org/10.1007/s11664-016-4797-6

[13] Sirait, M. and Motlan (2017) Synthesis and Morphology of Polyvinyl Alcohol/Zinc sulfide Nanocomposite. Materials Science and Engineering, 223, 1-6. https://doi.org/10.1088/1757-899X/223/1/012027

[14] Saikiaa, D., Saikiaa, P.K., Gogoi, P.K., Das, M.R., Sengupta, P. and Shelke, M.V. (2011) Synthesis and Characterization of CdS/PVA Nanocomposite Thin Films from a Complexing Agent Free System. Materials Chemistry and Physics, 131, 223-229. https://doi.org/10.1016/j.matchemphys.2011.09.011

[15] Adelifard, M., Eshghi, H. and Mohagheghi, M.M.B. (2012) Comparative Studies of Spray Pyrolysis Deposited Copper Sulfide Nanostructural Thin Films on Glass and FTO Coated Glass. Bulletin of Materials Science, 35, 739-744. https://doi.org/10.1007/s12034-012-0363-X

[16] Xu, J., Cui, X., Zhang, J., Liang, H., Wang, H. and Li, J. (2008) Preparation of CuS Nanoparticles Embedded in Poly(Vinyl Alcohol) Nanofibre via Electrospining. Bulletin of Materials Science, 31, 189-192. https://doi.org/10.1007/s12034-008-0033-1

[17] Yucel, E., Yucel, Y. and Gokhan, D. (2015) Computer Assisted Optimization of Copper Sulphide Thin Film Coating Parameters on Glass Substrate. Applied Surface Science, 351, 904-910. https://doi.org/10.1016/j.apsusc.2015.06.031

[18] Sabah, F.A., Ahmed, N.M., Hassan, Z. and Almessiere, M.A. (2017) A Novel CuS Thin Film Deposition Method by Laser-Assisted Spray Photolysis Deposition and its Application to EGFET. Sensors and Actuators B, 247, 197-215. https://doi.org/10.1016/j.snb.2017.03.020

[19] Adelifard, M., Eshghi, H. and Mohagheghi, M.M.B. (2012) An Invesiation on Substrate Temperature and Copper to Sulfur Molar Ratio on Optical and Electrical Properties of Nanostructural CuS Thin Films Prepared by Spray Pyrolysis Method. Applied Surface Science, 258, 5733-5738. https://doi.org/10.1016/j.apsusc.2012.02.079

[20] Ghobadi, N. (2013) Band Gap Determination Using Absorption Spectrum Fitting Procedure. International Nano Letters, 3, 2. https://doi.org/10.1186/2228-5326-3-2

[21] Bollero, A., Grossberg, M., Asenjo, B. and Gutierrez, M.T. (2009) CuS-Based Thin Film for Architectural Glazing Application Produced by Co-Evaporation: Morphology, Optical and Electrical Properties. Surface \& Coating Technology, 204, 593-600. https://doi.org/10.1016/j.surfcoat.2009.08.037 